\title{
PLOTHO, Erich-Christoph Freiherr von, Ritter, Domherren und Obristen. Familienchronik der Edlen Herren und Freiherrn von Plotho
}

Thierry Jacob

\section{(2) OpenEdition \\ Journals}

Édition électronique

URL : http://journals.openedition.org/ifha/1779

DOI : 10.4000/ifha. 1779

ISSN : 2198-8943

Éditeur

IFRA - Institut franco-allemand (sciences historiques et sociales)

Référence électronique

Thierry Jacob, «PLOTHO, Erich-Christoph Freiherr von, Ritter, Domherren und Obristen. Familienchronik der Edlen Herren und Freiherrn von Plotho », Revue de I'IFHA [En ligne], Date de recension, mis en ligne le 01 janvier 2009, consulté le 22 septembre 2020. URL : http://journals.openedition.org/ifha/1779 ; DOI : https://doi.org/10.4000/ifha.1779

Ce document a été généré automatiquement le 22 septembre 2020.

(CIFHA 


\title{
PLOTHO, Erich-Christoph Freiherr von, Ritter, Domherren und Obristen. Familienchronik der Edlen Herren und Freiherrn von Plotho
}

\author{
Thierry Jacob
}

1 Cet ouvrage généalogique consacré à une famille connue de la "petite " noblesse prussienne (l'une des ses représentantes, Elisabeth von Ardenne née von Plotho, ayant inspirée le personnage d'Effi Briest du roman éponyme de Theodor Fontane), s'inscrit dans la continuité des Familienchroniken éditées en nombre par les familles de la noblesse allemande depuis la seconde moitié du XIXe s.

2 En effet, si, désormais, cette chronique familiale ne se veut plus à strict usage interne, mais cherche à « mettre à la disposition de la science généalogique l'histoire du lignage »(p. 7), les continuités de conception l'emportent nettement sur l'innovation et l'analyse. Le sérieux et la rigueur, la précision des tableaux généalogiques et des notices biographiques, une présentation claire et illustrée constituent certes des points forts de l'ouvrage. Ce dernier respecte aussi tous les passages obligés que sont l'attention portée aux « temps anciens » de la famille et l'arsenal des intérêts généalogiques (médailles, armes et sceaux...). Enfin, l'ouvrage respecte pleinement sa raison d'être en ce que l'essentiel de son texte (250 pages) reconstitue, branche par branche, les biographies individuelles des différents membres de la famille, des époques lointaines jusqu'à nos jours, même si l'époque moderne détient une place plus importante. La somme d'informations est donc importante.

3 L'ouvrage pèche en revanche par une trop grande fidélité à un modèle de chronique familiale défini au XIXe s. mais qui, aujourd'hui, parât daté. Trop descriptif, il contextualise également peu les informations délivrées aussi bien en fonction du temps que thématiquement. Très peu d'informations sur les patrimoines hormis la liste des domaines dont les modes de gestion ne sont d'ailleurs pas ou peu précisés, des informations biographiques délivrées de façon « neutre » et linéaire et déconnectées du 
contexte (notamment pour la période nazie), des notices trop formelles et trop courtes pour les représentants les plus éminents du lignage, une exclusion des femmes par la justification qu'en se mariant elles perdent leur nom de jeune fille et ne sont donc plus des " von Plotho ", une histoire un peu arrêtée aux temps modernes au détriment du XIXe s. sont autant de manques laissant espérer que les chroniques familiales à venir essaieront de s'adapter plus dynamiquement aux attentes des historiens.

4 Thierry JACOB (Université Lumière-Lyon II) 